\title{
Doenças do sistema nervoso de bovinos no Mato Grosso do Sul: $1082 \operatorname{casos}^{1}$
}

\author{
Nickolly L. Kawski de Sá Ribas², Roosevelt Isaias Carvalho² , Ariany Carvalho dos \\ Santos $^{2}$, Renata A. Valençoela ${ }^{3}$, Anderson F. Gouveia ${ }^{4}$, Márcio Botelho de Castro ${ }^{5}$, \\ Ademar Etiro Mori ${ }^{6}$ e Ricardo A. Amaral de Lemos ${ }^{7 *}$
}

\begin{abstract}
Ribas N.L.K.S., Carvalho R.I., Santos A.C., Valençoela R.A., Gouveia A.F., Castro M.B., Mori A.E. \& Lemos R.A.A. 2013. [Diseases of the nervous system of cattle in Mato Grosso do Sul, Brazil: 1082 cases.] Doenças do sistema nervoso de bovinos no Mato Grosso do Sul: 1082 casos. Pesquisa Veterinária Brasileira 33(10):1183-1194. Laboratório de Anatomia Patológica, Faculdade de Medicina Veterinária e Zootecnia, Universidade Federal de Mato Grosso do Sul, Campo Grande, MS 79070-900, Brazil. E-mail: lap.famez@ufms.br

The aim of this study was to describe the types of diseases that affect the nervous system of cattle from the State of Mato Grosso do Sul, Brazil. A retrospective study from January 2008 to December 2012 was perfomed, based on reports of cattle autopsies autopsy carried out by the Laboratório de Anatomia Patológica (LAP), Faculdade de Medicina Veterinária e Zootecnia (FAMEZ), Universidade Federal de Mato Grosso do Sul (UFMS). The material came from cases attended and forwarded to LAP by practicing veterinarians autonomous and from the official veterinary service. From 1028 cases studied, 588 presented a history of neurological clinical signs, $341(53.75 \%)$ of which were diagnosed as affected bytrue neurological disease, and $247(46.25 \%)$ had inconclusive diagnosis. The clinical records were reviewed to determine epidemiology, clinical signs, and gross and histopathological features. The most frequent diseases were botulism (16.67\%), rabies (15.92\%), polioencephalomalacia (8.05\%), and herpesviral meningoencephalitis (4.31\%). Other conditions were diagnosed occasionally, and included non suppurative meningoencephalitis (2.62\%), suppurative meningoencephalitis $(1.50 \%)$, brain abscesses and osteomyelitis caused by spinal cord compression $(1.31 \%)$, tetanus $(1.12 \%)$, hypothermia $(0.94 \%)$, cerebral babesiosis $(0.75 \%)$, malignant catarrhal fever $(0.37 \%)$, and cases suggestive of oxalate poisoning $(0.19 \%)$. No cases with lesions that may suggest of bovine spongiform encephalopathy were observed.
\end{abstract}

INDEX TERMS: Rabies, botulism, polioencephalomalacia, herpesviral meningoencephalitis.

\footnotetext{
${ }^{1}$ Recebido em 5 de junho de 2013.

Aceito para publicação em 20 de junho de 2013.

${ }^{2}$ Programa de Pós-graduação em Ciência Animal, Faculdade de Medicina Veterinária e Zootecnia (FAMEZ), Universidade Federal de Mato Grosso do Sul (UFMS), Av. Senador Filinto Müller 2443, Campo Grande, MS 79074-460, Brasil.

${ }^{3}$ Programa de Residência em Medicina Veterinária, FAMEZ-UFMS, Campo Grande, MS.

${ }^{4}$ Graduando em Medicina Veterinária, Universidade de Brasília (UnB), Campus Darcy Ribeiro, Brasilia, DF 70910-970, Brasil.

${ }^{5}$ Laboratório de Patologia Veterinária, Hospital Veterinário (HoVet), UnB, Brasilia, DF.

${ }^{6}$ Médico Veterinário, Agência Estadual de Sanidade Animal e Vegetal (IAGRO), Av. Senador Filinto Müller 1146, Vila Ipiranga, Campo Grande, MS 79074-902.

${ }^{7}$ FAMEZ-UFMS, Campo Grande, MS 79074-902. *Autor para correspondência: lap.famez@ufms.br
}

RESUMO.- Foi realizado um estudo retrospectivo de janeiro de 2008 a dezembro de 2012 com base nos laudos de necropsia do Laboratório de Anatomia Patológica (LAP) da Faculdade de Medicina Veterinária e Zootecnia (FAMEZ), Universidade Federal de Mato Grosso do Sul (UFMS), com o intuito de descrever quais as doenças que afetam o sistema nervoso de bovinos que ocorrem no Mato Grosso do Sul. Os casos consistiam de acompanhados por técnicos do LAP e encaminhados por médicos veterinários que atuam no campo (autônomos ou do serviço veterinário oficial). De 1082 materiais analisados, 588 apresentavam histórico de sinais clínicos neurológicos. Destes, 341 (53,75\%) tiveram diagnóstico correspondente a doenças neurológicas e $247(46,25 \%)$ tiveram diagnóstico inconclusivos. As fichas clínico epidemiológicas foram revisadas para deter- 
minar dados referentes a epidemiologia, aos sinais clínicos e às alterações macroscópicas e microscópicas. 0 botulismo $(16,67 \%)$, a raiva $(15,92 \%)$, a polioencefalomalacia $(8,05 \%)$ e a encefalite por herpesvirus bovino $(4,31 \%)$ foram as enfermidade de maior frequência. Outras doenças como meningoencefalite não supurativa $(2,62 \%)$, meningoencefalite supurativa $(1,50 \%)$, abscessos cerebrais e osteomielite por compressão medular $(1,31 \%)$, tétano $(1,12 \%)$, hipotermia $(0,94 \%)$, babesiose cerebral $(0,75 \%)$, febre catarral maligna $(0,37 \%)$ e lesões sugestivas de intoxicação por oxalato $(0,19 \%)$ foram ocasionalmente diagnosticadas. Em nenhum dos casos foram observadas lesões que pudessem sugerir encefalopatia espongiforme bovina.

TERMOS DE INDEXAÇÃO: Raiva, botulismo, polioencefalomalacia, encefalite por herpesvirus bovino.

\section{INTRODUÇÃO}

O Laboratório de Anatomia Patológica (LAP) da Faculdade de Medicina Veterinária e Zootecnia, Universidade Federal de Mato Grosso do Sul, atuou como Laboratório credenciado pelo Ministério da Agricultura (MAPA) no Programa Nacional de Vigilância das Encefalopatias Transmissíveis de janeiro de 2000 a dezembro de 2007. Durante este período estudou-se o sistema nervoso dos bovinos de forma sistematizada, conforme estabelecido pelo Programa Nacional de Controle da Raiva dos herbívoros e Outras Encefalopatias (PNCRH)(BRASIL 2002). Essa atividade gerou importantes informações sobre as doenças que afetam o sistema nervoso dos bovinos e possibilitou melhor avaliação da metodologia de diagnóstico usada, pois embora existam diversos trabalhos descrevendo doenças que afetam o sistema nervoso em bovinos (Riet-Correa et al. 1998, Sanches et al. 2000, Galiza et al. 2010, Rissi et al. 2010) há poucos estudos sistematizados sobre as mesmas.

A partir de janeiro de 2008, com base nos resultados obtidos nos anos anteriores, foram introduzidas alterações nos procedimentos de rotina do LAP. Essas alterações visavam melhorar a eficiência do diagnóstico e corrigir possíveis falhas no envio de materiais necessários para a formulação de diagnósticos adequados. Também foram realizadas alterações nas fichas de colheita de dados, como a inclusão da colheita de dados de rebanho e dos sinais clínicos observados.

O objetivo deste trabalho é descrever as principais doenças do sistema nervoso de bovinos diagnosticados no LAP de janeiro de 2008 a dezembro de 2012, descrevendo seus aspectos epidemiológicos, sinais clínicos, achados de necropsia e o diagnóstico laboratorial visando fornecer informações relevantes e aplicáveis sobre a ocorrência das mesmas à rotina dos médicos veterinários autônomos e oficiais.

\section{MATERIAL E MÉTODOS}

Realizou-se uma pesquisa retrospectiva nos laudos de necropsia de bovinos com doença neurológica no Laboratório de Anatomia Patológica (LAP) da Faculdade de Medicina Veterinária e Zootecnia (FAMEZ), Universidade Federal de Mato Grosso do Sul (UFMS), Campo Grande, MS, de janeiro de 2008 a dezembro de 2012. Foram avaliados os aspectos de anamnese (raça, sexo dos animais afetados) e epidemiológicos (sazonalidade e ciclicidade da doença), obtidos nos dados das fichas clínico epidemiológicas confeccionadas por médicos veterinários do LAP ou por profissionais autônomos ou do serviço veterinário oficial. Nos casos em que mais de um material de uma mesma propriedade foram enviados, estes foram agrupados por surtos.

Foram considerados neste levantamento os casos que apresentavam sinais clínicos neurológicos, incluindo os que tiveram diagnóstico de doença neurológica específica e os inconclusivos. Os casos experimentais e amostras originárias de outro estado que não Mato Grosso do Sul foram excluídos do estudo.

Para a determinação da ocorrência, da sazonalidade e das faixas etárias dos bovinos acometidos pelas diferentes enfermidades, foi considerado o somatório dos casos acompanhados por médicos veterinários do LAP e dos casos encaminhados por médicos veterinários do serviço oficial e da iniciativa privada. Para cálculo de morbidade e letalidade foram considerados apenas os surtos em que a população sob risco foi informada. Apenas nos casos de raiva, para o cálculo da morbidade, a população total foi considerada como a população sob risco. Os sinais clínicos relatados foram agrupados seguindo metodologia já descrita (Riet-Correa et al. 2002, Lima et al. 2005).Todas as amostras foram fixadas em formol a 10\% e encaminhadas para diafanização e embebição em parafina, sendo depois cortadas em secções de $5 \mu \mathrm{m}$ e coradas com hematoxilina e eosina para a realização do diagnóstico histológico.

Casos suspeitos de raiva foram encaminhados ao Laboratório de Diagnóstico de Doenças Animais e Análise de Alimentos (LADDAN) da Agência Estadual de Defesa Sanitária Animal e Vegetal (IAGRO) para a realização das técnicas de imunofluorescência direta (IFD) e inoculação intracerebral em camundongos lactentes (IIC). A imuno-histoquímica (IHQ) foi realizada no LAP como meio de diagnóstico em 95 casos de raiva (Pedroso et al. 2008), utilizando-se anticorpo policlonal (Chemicon \#5199) e em 30 casos de encefalite por herpesvirus bovino (Meyer et al. 2001) com anticorpo monoclonal (VRMD \#L6G).

Para o diagnóstico de botulismo os principais critérios adotados foram a ausência de lesões macro e microscópicas que justificassem os sinais clínicos observados, o resultado negativo para raiva na IFD e IIC e achados clínicos e epidemiológicos característicos de botulismo (existência de fonte de toxinas: como carcaças no pasto ou aguadas, silagem, cama de frango, palhadas). Os diagnósticos de botulismo e sugestivos de botulismo foram agrupados; foram considerados como sugestivos de botulismo os casos não acompanhados pela equipe do LAP, sem lesão histológica e com resultado negativo para raiva na IFD e IIC.

Devido a ocorrência de numerosos surtos de miopatias tóxicas a partir de dezembro de 2010 (Santos et al. 2011), procedeu-se a alteração na metodologia de diagnóstico na rotina do LAP. A partir daquela data, as amostras de bovinos que apresentavam distúrbios compatíveis com botulismo e dos quais não foram encaminhados fragmentos de musculatura esquelética, passaram a ser considerados como inconclusivos.

Para o diagnóstico de babesiose cerebral foram consideradas as lesões macroscópicas de coloração róseo-cereja da substância cinzenta do encéfalo, a histopatologia e realização de impressões de fragmentos do córtex encefálico corados por panótico rápido para pesquisa de protozoários em hemácias como técnica complementar.

As doenças com frequência superior a $4 \%$ foram discutidas separadamente, e as demais agrupadas sob a designação de "outras doenças". Casos com diagnóstico morfológico de meningoencefalite não supurativa foram considerados no grupo de outras doenças. 
Salienta-se que os dados obtidos neste trabalho correspondem apenas ao momento da visita à propriedade, do encaminhamento do bovino para a necropsia ou recebimento do material no LAP, não tendo havido acompanhamento posterior dos surtos.

\section{RESULTADOS}

De janeiro de 2008 a dezembro de 2012 foram encaminhadas 1082 amostras de bovinos dos quais 588 apresentavam sinais clínicos neurológicos. Desses, 341 (53,75\%) diagnósticos corresponderam a doenças com sintomatologia nervosa e $247(46,25 \%)$ amostras apresentaram resultados inconclusivos. Embora grande parte dos materiais diagnosticados como inconclusivos não estivessem acompanhados de histórico clínico, os mesmos eram previamente encaminhados para o diagnóstico laboratorial de raiva, presumindo-se que eram provenientes de bovinos com distúrbios neurológicos.

Entre os casos com diagnóstico inconclusivo, as falhas apontadas no envio do material foram a falta de envio de partes anatômicas pertinentes do sistema nervoso $(55,06 \%)$, falta de histórico clínico $(44,53 \%)$, autólise $(8,1 \%)$ e congelamento das amostras $(2,02 \%)$.

Três casos de polioencefalomalacia relatados no presente estudo foram descritos anteriormente por Sant'Ana et al. (2009).

No Quadro 1 estão relacionadas por ordem de prevalência as doenças caracterizadas por distúrbios neurológicos diagnosticadas pelo LAP no período de abrangência do estudo, descritos por número de casos e agrupados em surtos. A sazonalidade e a ciclicidade das principais doenças estão expressas nas Figuras. 1 e 2.

Dados como idade, sexo e ocorrência em diferentes espécies são apresentados no Quadro 2 de forma comparativa entre as principais doenças diagnosticadas.

Dados de morbidade e letalidade das principais doenças diagnosticadas estão descritos nos Quadros 3 e 4, respectivamente.

Dados epidemiológicos referentes aos surtos de botulismo são demonstrados no Quadro 5.

Quadro 1. Diagnósticos realizados em 534 surtos com sinais clínicos neurológicos, pelo LAP/FAMEZ/UFMS no período de janeiro de 2008 a dezembro de 2012

\begin{tabular}{lccc}
\hline \multicolumn{1}{c}{ Diagnóstico } & $\begin{array}{c}\text { No de } \\
\text { casos }\end{array}$ & $\begin{array}{c}\text { No de } \\
\text { surtos }\end{array}$ & $\%$ \\
\hline Botulismo & 102 & 89 & 16,67 \\
Raiva & 100 & 85 & 15,92 \\
Polioencefalomalacia (PEM) & 44 & 43 & 8,05 \\
Encefalite por herpesvírus bovino (BoHV) & 33 & 23 & 4,31 \\
$\quad$ Outras doenças & & & \\
Meningoencefalite não supurativa (MENS) & 14 & 14 & 2,62 \\
Meningoencefalite supurativa (MES) & 9 & 8 & 1,50 \\
Abscessos no sistema nervoso/ & & & \\
$\quad$ osteomielite com compressão medular & 7 & 7 & 1,31 \\
Tétano & 6 & 6 & 1,12 \\
Hipotermia & 18 & 5 & 0,94 \\
Babesiose cerebral & 4 & 4 & 0,75 \\
Febre Catarral Maligna (FCM) & 2 & 2 & 0,37 \\
Sugestivo de intoxicação por oxalato & 2 & 1 & 0,19 \\
Inconclusivos & 247 & 247 & 46,25 \\
TOTAL GERAL & 588 & 534 & 100
\end{tabular}

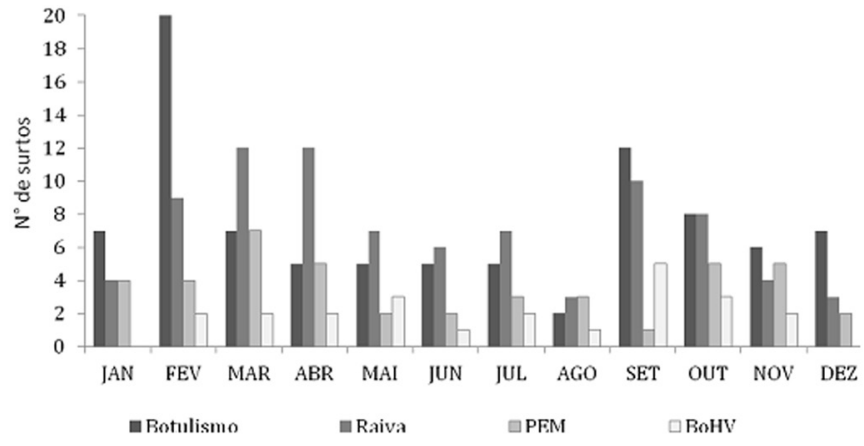

Fig.1. Sazonalidade dos surtos das principais doenças com sinais clínicos neurológicos de bovinos diagnosticadas no LAP/FAMEZ/UFMS, no período de janeiro de 2008 a dezembro de 2012.

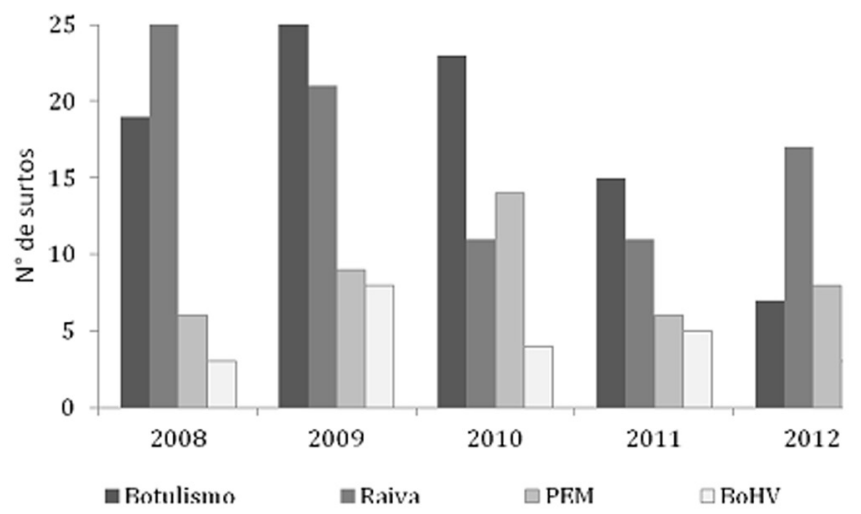

Fig.2. Ciclicidade dos surtos das doenças com sinais clínicos neurológicos de bovinos de maior ocorrência diagnosticadas no LAP/FAMEZ/UFMS, no período de janeiro de 2008 a dezembro de 2012.

Quadro 2. Dados epidemiológicos referentes aos surtos de doenças com sinais clínicos neurológicos diagnosticadas no LAP/FAMEZ/UFMS no período de janeiro de 2008 a dezembro de 2012

\begin{tabular}{|c|c|c|c|c|c|c|}
\hline \multirow[t]{2}{*}{ Doença } & \multirow[t]{2}{*}{ Idade } & \multicolumn{3}{|c|}{ Diferentes espécies acometidas } & \multicolumn{2}{|c|}{ Sexo (casos) } \\
\hline & & Sim & Não & NI & $\mathrm{M}$ & $\mathrm{F}$ \\
\hline Botulismo & $12->48 m$ & - & 84 & 4 & 23 & 79 \\
\hline Raiva & $40 \mathrm{~d}->48 \mathrm{~m}$ & $11^{*}$ & 69 & 5 & 37 & 63 \\
\hline PEM & $9->48 m$ & - & 43 & - & 25 & 19 \\
\hline BoHV & $6->48 m$ & - & 19 & 4 & 30 & 3 \\
\hline
\end{tabular}

$\overline{\mathrm{NI}}=$ não informado; ${ }^{*}$ bovinos e equinos.

Quadro 3. Coeficiente de morbidade das principais doenças do sistema nervoso diagnosticadas no LAP/FAMEZ/UFMS no período de janeiro de $\mathbf{2 0 0 8}$ a dezembro de 2012

\begin{tabular}{|c|c|c|c|c|c|c|c|}
\hline & $0-1,0 \%$ & $1,1-2,0 \%$ & $2,1-3,0 \%$ & $3,1-4,0 \%$ & $4,1-5,0 \%$ & $5,1-10,0 \%$ & $>10,0 \%$ \\
\hline $\begin{array}{c}\text { Botulismo } \\
(\mathrm{n}=58)\end{array}$ & 9 & 17 & 5 & 9 & 3 & 7 & 8 \\
\hline $\begin{array}{l}\text { Raiva } \\
(\mathrm{n}=73)\end{array}$ & 42 & 14 & 5 & 2 & 4 & 5 & 1 \\
\hline $\begin{array}{l}\text { PEM } \\
(\mathrm{n}=31)\end{array}$ & 9 & 10 & 4 & 2 & 2 & - & 4 \\
\hline $\begin{array}{l}\text { BoHV } \\
(n=11)\end{array}$ & 3 & 3 & 2 & 2 & 1 & - & - \\
\hline
\end{tabular}

Nos Quadros 6 e 7 constam os dados referentes aos surtos de raiva (condições de vacinação e espoliação por morcegos) e a relação do tipo de morte (natural ou eutanásia) com as diferentes técnicas de diagnóstico empregadas.

Os sinais clínicos observados nos surtos acompanhados 
Quadro 4. Coeficiente de letalidade das principais doenças do sistema nervoso diagnosticadas no LAP/FAMEZ/UFMS no período de janeiro de $\mathbf{2 0 0 8}$ a dezembro de $\mathbf{2 0 1 2}$

\begin{tabular}{|c|c|c|c|c|c|c|c|}
\hline & $30-40 \%$ & $41-50 \%$ & $51-60 \%$ & $61-70 \%$ & $71-80 \%$ & $81-90 \%$ & $91-100 \%$ \\
\hline $\begin{array}{c}\text { Botulismo } \\
(\mathrm{n}=75)\end{array}$ & 3 & 4 & 2 & 2 & 4 & 2 & 58 \\
\hline $\begin{array}{l}\text { Raiva } \\
(\mathrm{n}=82)\end{array}$ & 1 & - & - & 6 & 2 & 4 & 69 \\
\hline $\begin{array}{c}\text { PEM } \\
(n=43)\end{array}$ & - & 5 & 1 & - & 2 & - & 35 \\
\hline $\begin{array}{l}\mathrm{BoHV} \\
(\mathrm{n}=21)\end{array}$ & 2 & 2 & - & 1 & - & 2 & 14 \\
\hline
\end{tabular}

Quadro 5. Dados de suplementação, destino de carcaças e vacinação referentes aos 89 surtos de botulismo diagnosticados no LAP/FAMEZ/UFMS no período de janeiro de 2008 a dezembro de 2012

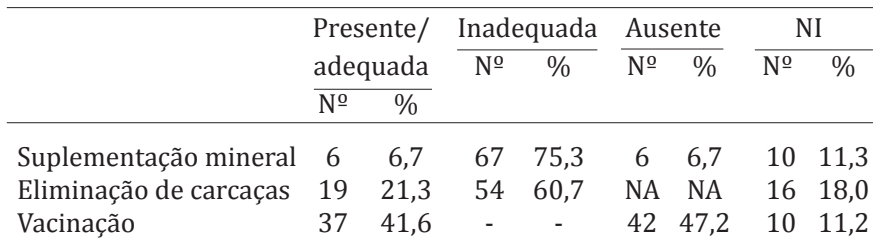

NI = não informado; NA = não se aplica.

Quadro 6. Condições da vacinação e espoliação por morcegos nos 85 surtos de raiva diagnosticados no LAP/FAMEZ/UFMS no período de janeiro de 2008 a dezembro de 2012

\begin{tabular}{|c|c|c|c|c|c|c|c|c|}
\hline & \multirow{2}{*}{\multicolumn{2}{|c|}{$\begin{array}{l}\text { Presente/ } \\
\text { adequada }\end{array}$}} & \multicolumn{2}{|c|}{ Inadequada } & \multicolumn{2}{|c|}{ Ausente } & \multicolumn{2}{|c|}{ NI } \\
\hline & & & \multirow[t]{2}{*}{ № } & \multirow[t]{2}{*}{$\%$} & \multirow[t]{2}{*}{ № } & \multirow[t]{2}{*}{$\%$} & \multirow[t]{2}{*}{ № } & \multirow[t]{2}{*}{$\%$} \\
\hline & № & $\%$ & & & & & & \\
\hline Vac & 17 & 20,0 & 21 & 24,7 & 32 & 37,7 & 15 & 17,6 \\
\hline Espoliação por morcegos & 54 & 63,5 & NA & NA & 3 & 3,5 & 28 & 33,0 \\
\hline
\end{tabular}

NI = não informado; NA = não se aplica.

Quadro 7. Relação do tipo de morte e técnica de diagnóstico em 100 casos de raiva diagnosticados no LAP/FAMEZ/UFMS no período de janeiro de 2008 a dezembro de 2012

\begin{tabular}{lcccc}
\hline & Eutanasiados & Morte natural & NI & Total \\
\hline IFD, IIC e IHQ positivas & 36 & 48 & 5 & 89 \\
IFD negativa e IIC e IHQ positiva & 0 & 4 & 0 & 4 \\
IFD e IIC negativas e IHQ positiva & 0 & 2 & 0 & 2 \\
IFD e IIC positivas* & 3 & 2 & 0 & 5
\end{tabular}

$\mathrm{NI}=$ não informado; ${ }^{*}$ não realizada $\mathrm{IHQ}$.

por médicos veterinários do LAP e dos materiais recebidos (serviço oficial e iniciativa privada) estão descritos no Quadro 8.

\section{DISCUSSÃO}

As doenças do sistema nervoso constituem importantes causas de mortalidade em bovinos em Mato Grosso do Sul. Essas doenças representaram 31,52\% do total de diagnósticos realizados no período de 5 anos estudado. 0 botulismo $(16,67 \%)$, a raiva $(15,92 \%)$, a PEM $(8,05 \%)$ e o BoHV $(4,31 \%)$ foram as principais doenças diagnosticadas. Outras doenças ou diagnósticos morfológicos como tétano, hipotermia, abscessos no sistema nervoso (SN) e/ou osteomielite de vértebra com compressão medular, babesiose cerebral, intoxicação por oxalato, febre catarral maligna
Quadro 8. Sinais clínicos das principais doenças do sistema nervoso diagnosticadas no LAP/FAMEZ/UFMS no período de janeiro de 2008 a dezembro de 2012

\begin{tabular}{|c|c|c|c|c|c|}
\hline & & $\begin{array}{c}\text { Botulismo } \\
(\mathrm{n}=102)\end{array}$ & $\begin{array}{c}\text { Raiva } \\
(\mathrm{n}=100)\end{array}$ & $\begin{array}{c}\text { PEM } \\
(\mathrm{n}=44)\end{array}$ & $\begin{array}{c}\text { BoHV } \\
(n=33)\end{array}$ \\
\hline \multirow[t]{8}{*}{ Cérebro } & Agressividade & 8 & 20 & 3 & 4 \\
\hline & Anorexia & 2 & 2 & 1 & 10 \\
\hline & Apatia & 1 & 1 & 2 & 8 \\
\hline & Bruxismo & 1 & 1 & - & 5 \\
\hline & Cegueira & 1 & 16 & 17 & 18 \\
\hline & Fotofobia & - & 3 & - & - \\
\hline & Movimentos de pedalagem & 25 & 33 & 20 & 10 \\
\hline & Mudanças de atitude & 6 & 20 & 7 & 3 \\
\hline \multirow{9}{*}{$\begin{array}{l}\text { Tronco } \\
\text { encefálico }\end{array}$} & Ataxia & 20 & 1 & 10 & 8 \\
\hline & Dificuldade de deglutição & 2 & - & - & 1 \\
\hline & Flacidez da língua & 10 & - & 1 & 3 \\
\hline & Nistagmo & 1 & 9 & 4 & 1 \\
\hline & Pupilas dilatadas (midríase) & - & 2 & 3 & - \\
\hline & Salivação & - & - & - & 5 \\
\hline & Depressão & 24 & 19 & 15 & 15 \\
\hline & Convulsões & - & 3 & 3 & - \\
\hline & Sialorréia & 7 & 26 & 8 & 13 \\
\hline \multirow[t]{3}{*}{ Cerebelo } & Opistótono & 16 & 23 & 19 & 10 \\
\hline & Tremores musculares & 11 & 27 & 10 & 9 \\
\hline & Dismetria & 2 & 3 & 2 & 1 \\
\hline \multirow{7}{*}{$\begin{array}{l}\text { Medula } \\
\text { espinhal }\end{array}$} & Ausência de reflexo anal & 2 & 4 & - & - \\
\hline & Decúbito esternal & 20 & 6 & 8 & 5 \\
\hline & Decúbito lateral & 17 & 12 & 2 & 10 \\
\hline & Incoordenação & 36 & 64 & 20 & 16 \\
\hline & Paralisia da cauda & 2 & 1 & - & - \\
\hline & Paralisia dos membros pélvic & vicos73 & 65 & 24 & 8 \\
\hline & Tenesmo & 1 & 2 & 1 & - \\
\hline
\end{tabular}

(FCM), meningite supurativa e meningoencefalite não supurativa foram relatadas esporadicamente, perfazendo um total de 8,8\% das doenças. Em levantamento anteriormente realizado as doenças caracterizadas por sinais neurológicos representaram 44,5\%, sendo destes $29 \%$ casos de raiva, $23 \%$ casos de botulismo, 20\% meningoencefalite não supurativa, $12 \%$ outras doenças com sinais clínicos neurológicos, 11\% PEM e 5\% de BOHV (Lemos 2005). Algumas doenças diagnosticadas anteriormente no estado como listeriose, intoxicação por chumbo, toxemia da prenhez, meningoencefalite tromboembólica, intoxicação por ureia e intoxicação por abamectina (Lemos 2005), intoxicação por Tetrapterys multiglandulosa (Carvalho et al. 2006), não foram diagnosticadas neste estudo.

Esses resultados demonstram que as doenças de maior prevalência no estado, embora possam apresentar variações são essencialmente as mesmas nos dois períodos estudados. Algumas doenças de baixa prevalência e ocorrência esporádica no levantamento anterior como tétano, febre catarral maligna, meningite supurativa, abscessos no $\mathrm{SN}$, repetiram esta característica no presente estudo.

Quatro casos de babesiose cerebral e dois casos de intoxicação por oxalato foram diagnosticados neste estudo. Essas doenças não estavam presentes em levantamento realizado de janeiro de 2000 a dezembro de 2003 no LAP (Lemos 2005).

Esses dados demonstram que para uma estimativa adequada da ocorrência das doenças de importância no estado, os levantamentos devem abranger séries históricas de no mínimo dez anos. Fato semelhante tem sido observado 
em outros estudos (Riet-Correa et al. 1998, Sanches et al. 2000, Galiza et al. 2010, Rissi et al. 2010) realizados em outros estados cuja metodologia baseia-se em levantamentos de séries históricas nos quais algumas doenças apresentam alta frequência e ocorrem de maneira constante enquanto outras são diagnosticadas esporadicamente.

A seguir serão discutidos os aspectos epidemiológicos, clínicos e patológicos das principais doenças diagnosticadas no período estudado.

\section{Botulismo}

Os casos de botulismo ocorreram em todos os meses do ano acometendo bovinos de praticamente todas as faixas etárias, embora a maioria dos surtos tenha ocorrido entre os meses de setembro e março acometendo animais com idade acima de 19 meses. Esses resultados demonstram que embora a maioria dos surtos diagnosticados esteja relacionada à osteofagia (53 surtos), outras fontes de intoxicação como água ou alimento (3 surtos) também foram relatadas. Fato semelhante foi observado em estudos anteriores nos quais a predominância de surtos associados à osteofagia ocorreu entre os meses de outubro e maio acometendo bovinos de 2 a 3,5 anos. Esta característica epidemiológica explica-se pelo fato de que nesse período há uma maior oferta de proteína (que eleva a necessidade de fósforo) e a ocorrência de chuvas impede uma suplementação mineral adequada (Dutra 2001).

Considerando-se como os principais fatores de risco para a ocorrência do botulismo a presença de carcaças no pasto, associada à suplementação mineral inadequada e a ausência ou realização inadequada de vacinação (Dutra 2001), os dados obtidos no presente trabalho reforçam esta relação (Quadro 3). Salienta-se que esses dados foram obtidos a partir de informações fornecidas pelos responsáveis pela fazenda e não foram realizadas inspeções in loco, de modo que o número de casos pode estar superestimado. Para avaliar corretamente a eficiência da vacinação é necessário saber-se o calendário de vacinação das propriedades.

Os coeficientes de morbidade (0,17-33,3\%) apresentam grande variação, no entanto esses números devem ser vistos com cautela, pois se referem apenas ao momento de colheita das informações na ficha epidemiológica, podendo assim ter ocorrido novos casos após a realização do diagnóstico. Considerando-se que o botulismo ocorre quando os bovinos têm acesso a uma fonte de toxina e que esta geralmente está localizada em uma determinada área da propriedade, a abordagem mais adequada para o estudo de morbidade é avaliar este coeficiente na população sob risco. Em 44 casos as fichas epidemiológicas não continham esta informação. No entanto, nos laudos em que o dado foi incluído (58 surtos), o coeficiente de morbidade nas populações sob risco variou de $0,17 \%$ a $33,33 \%$ (média $5,08 \%$ ). Estudo anterior descreve coeficientes de morbidade variando de 9,19\% nos surtos associados à osteofagia, já em surtos relacionados à alimentação esse coeficiente variou para cama de frango (31,33\%), silagem $(6,81 \%)$ e milho (29,34\%) (Dutra 2001). Dutra, Döbereiner \& Souza (2005) relatam um coeficiente de morbidade de 3,47\% a $100 \%$ em surtos de bovinos alimentados com cama de frango. Embora raciocínio semelhante possa ser feito em relação à letalidade, os valores médios indicam que esse é elevado na maioria dos surtos $(90,83 \%)$, corroborando com relatos anteriores que descrevem letalidade média variando de $84,63 \%$ a $99,22 \%$, dependendo da origem da intoxicação (Dutra 2001) e 60,52\% a 100\% em surtos relacionados a ingestão de cama de frango (Dutra, Döbereiner \& Souza 2005).

Embora a maioria dos sinais clínicos relatados esteja de acordo com o quadro clínico de botulismo, a frequência dos mesmos apresentou grande variação. Sinais clínicos considerados como frequentes e importantes para o diagnóstico como paralisia flácida dos membros, respiração abdominal, paralisia de cauda, incoordenação motora, diminuição do tônus da língua e tentativa de levantar sem êxito (Riet-Correa, Schild \& Fernandes 1998, Dutra 2001, Barros et al. 2006) não foram descritos ou foram mencionados em pequena parte dos casos. Diversas causas podem contribuir para isto, uma destas pode ser que o atendimento ao surto muitas vezes é realizado com o animal morto ou em estágio terminal, impossibilitando ou dificultando a realização do exame clínico. Nestes casos as informações sobre possíveis sinais clínicos são obtidos dos funcionários ou proprietários e, portanto, não são precisos. Outra possível causa é a falta de uma conduta sistemática pelos médicos veterinários de uma conduta sistematizada para realização do exame clínico de bovinos com distúrbios nervosos (Riet-Correa, Riet-Correa \& Schild 2002). 0 relato de sinais clínicos que não são compatíveis com botulismo como cegueira, opistótono, ataxia, depressão, movimentos de pedalagem e tetania, provavelmente estão relacionados à interpretação incorreta dos sinais neurológicos.

Em nenhum dos casos foram encontradas alterações macroscópicas ou histológicas significativas, embora eventualmente tenham sido descritas alterações como congestão ou focos de hemorragia no intestino delgado. Estas alterações, por não estarem relacionadas a outras lesões importantes ou manifestações clínicas foram consideradas como inespecíficas de acordo com Njaa et al. (2012).

A correta interpretação dos sinais clínicos, achados de necropsia e histopatológicos são fundamentais para o estabelecimento do diagnóstico do botulismo, pois esta doença não produz lesões significativas e o diagnóstico laboratorial através da detecção da toxina pela técnica de soroneutralização em camundongos possui baixa sensibilidade (Dutra 2001) de maneira que o diagnóstico deve ser realizado baseado na epidemiologia (ingestão da toxina), quadro clínico e ausência de lesões macroscópicas e histológicas (Dutra 2001, Dutra et al. 2005, Barros et al. 2006, Galiza et a. 2010).

Ressalta-se a importância da realização do diagnóstico diferencial no qual devem ser incluídas além das doenças que afetam o sistema nervoso como a raiva, as doenças que afetam o sistema músculo esquelético como miopatias nutricionais, intoxicação por ionóforos e por Senna occidentalis e Senna obtusifolia (fedegoso), ou ainda doenças que causam distúrbios nervosos que também afetam outros sistemas (Barros et al. 2006). Casos de intoxicação por fedegoso onde os animais entram em decúbito per- 
manecendo alertas, podem ser confundidos com botulismo. Entretanto, alterações de necropsia (áreas pálidas na musculatura esquelética) e histopatológicas (necrose e degeneração de fibras musculares) características dessa intoxicação (Carmo et al. 2011), não estão presentes no botulismo, demonstrando a necessidade de envio da musculatura esquelética para o diagnóstico diferencial. Este raciocínio aplica-se para outras miopatias como as nutricionais. Um sinal clínico considerado importante no botulismo (Dutra 2001) e não observado em nenhum caso de intoxicação por fedegoso é a paralisia de cauda.

Outra doença recentemente diagnosticada no estado, a intoxicação por Simarouba versicolor, que provoca sinais clínicos como relutância em andar, debilidade, decúbito e morte de evolução rápida, pode ser confundida com botulismo. Esta intoxicação causa lesões de enterite necrosante e necrose de tecido linfoide em bovinos (Carvalho et al. 2013), porém fragmentos do intestino (incluindo as Placas de Peyer) e linfonodos muitas vezes não são encaminhados para o exame histopatológico, impossibilitando a realização do diagnóstico diferencial.

\section{Raiva}

A exemplo dos surtos de botulismo, os surtos de raiva ocorreram em todos os meses do ano afetando bovinos de todas as idades. Foi observada uma maior prevalência em bovinos com menos de 2 anos (55\%). Este fato pode estar relacionado à menor imunidade dos animais jovens devido a não revacinação 30-40 dias após a primeira vacinação ou a um retardo na idade da primovacinação que deve ser realizada aos 3-4 meses de idade. Esta mesma situação foi observada na região Nordeste (Lima et al. 2005) e em relatos anteriores no MS (Langohr et al. 2003, Lemos 2005), onde há maior prevalência em animais jovens. Bovinos de até um mês e acima de 48 meses apresentaram menor frequência. 0 menor número de casos acima de 48 meses pode ser explicado pelo fato de ocorrer uma maior frequência de vacinação com o avançar da idade, visto que a vacinação antirrábica tem periodicidade anual (Brasil 2002) e a natureza proteica do vírus o torna um bom indutor de resposta imune (Kotait et al. 1998). Em bovinos até 1 mês, a menor frequência de diagnóstico é justificada pela capacidade de transferência de imunidade da vaca ao bezerro através do colostro (Brambell 1958).

A metodologia empregada para análise da idade dos bovinos neste estudo, embora forneça uma estimativa da distribuição das doenças conforme a faixa etária, não é a forma mais adequada de interpretação deste parâmetro, pois os dados referem-se aos casos encaminhados ao laboratório. Considerando que em um surto não são encaminhados materiais de todos os animais mortos, a mensuração exata da idade dos animais acometidos deveria ser colhida avaliando-se a faixa etária de todos os animais acometidos no surto.

Outra diferença entre a raiva e o botulismo foi a ocorrência de casos de raiva em diferentes pastos, afetando diferentes espécies e também propriedades vizinhas. Essas características epidemiológicas são importantes para a elaboração da suspeita diagnóstica (Fernandes \& Riet-Correa 2007).
No presente estudo a raiva ocorreu em todos os meses do ano, sendo os meses de fevereiro, março, abril, setembro e outubro os de maior ocorrência, e os picos nos meses de março e abril. A maior ocorrência de casos nesses meses pode ser atribuída ao manejo reprodutivo dos rebanhos bovinos no MS, cuja estação de parição concentra-se nos meses de agosto a novembro. Assim, os bezerros estariam mais susceptíveis nos meses de março e abril devido ao declínio dos anticorpos da imunidade colostral. Outros autores também descrevem a ocorrência de sazonalidade, entretanto em outros meses do ano, entre abril a agosto (Mori \& Lemos 1998), abril a junho (outono) (Mori et al. 2004). Em outros estados, como Minas Gerais e São Paulo a predominância é relatada de abril a agosto (Silva et al. 2001) e no Nordeste entre março e agosto (Lima et al 2005). A sazonalidade é atribuída ao ciclo biológico do morcego. Durante a primavera (período de acasalamento) ocorrem disputas entre os machos pelas fêmeas, as quais resultam em brigas, ocasionando ferimentos que facilitam a disseminação da infecção pelo vírus no interior das colônias e entre as colônias. Os picos de surtos ocorreriam no outono devido ao período de incubação da doença nos morcegos e nos bovinos espoliados (Mori \& Lemos 1998).

O número de diagnósticos de raiva apresentou declínio nos anos de 2008 a 2010, mantendo-se estável no ano de 2011 e elevando-se novamente no ano de 2012. A diminuição de casos seguida da elevação pode estar relacionada à ocorrência da ciclicidade da raiva no MS, fato este apontado anteriormente por autores que mencionam ciclos com periodicidade de aproximadamente 7 anos (Mori \& Lemos 1998). A ciclicidade da doença também é relatada no estado do Rio Grande do Sul (Teixeira et al. 2008), o que de acordo com Turner (1975), em regiões endêmicas a cada 2 a 3 anos ocorrem surtos limitados a população de morcegos. Isto se deve aparentemente ao maior número de morcegos infectados nos picos da doença nos herbívoros, ocorrendo período de declínio para repovoamento e re-infecções das colônias de morcegos já que o crescimento das mesmas é lento (Barros et al. 2006).

Considerando-se como principais fatores de risco para raiva a ocorrência de morcegos hematófagos na propriedade, associado a não vacinação dos bovinos, os dados obtidos no presente estudo reforçam esta observação. A espoliação por morcegos hematófagos foi relatada em 52 surtos. Em 32 surtos os bovinos não eram vacinados e em 21 surtos realizada de forma inadequada. Ressalta-se que por vacinação adequada considerou-se a realização de uma dose vacinal, seguida de reforço 30 dias e após a realização deste, revacinações anuais (Barros et al. 2006). No entanto, é possível que muitos desses casos a vacinação ou o reforço vacinal tenham sido realizados quando os animais já estavam no período de incubação da doença sendo, portanto, ineficaz.

Uma condição relatada com frequência no MS é o hábito dos produtores vacinarem seus animais após o diagnóstico de raiva em propriedades vizinhas. Este procedimento não oferece a eficácia pretendida uma vez que o período de incubação em bovinos é de 2 a 12 semanas (Maxie 2007).

Os coeficientes de morbidade e letalidade apresenta- 
ram ampla variação, sendo se 0,04 a $64,71 \%$ e 33,3 a 100\%, respectivamente. No entanto, como descrito anteriormente estes números expressam o número de doentes e mortos no momento da colheita das informações para as fichas epidemiológicas. Dessa forma, é provável a ocorrência de novos casos após a realização do diagnóstico e a morte de animais doentes no momento da colheita. Ressalta-se que o coeficiente de letalidade da raiva é invariavelmente 100\% (Mori \& Lemos 1998). Quanto aos coeficientes de morbidade em estudos realizados em diferentes regiões do Brasil, variaram de 0,03-10\% (Langohr et al. 2003) e 0,12-4\% (Lemos 2005) no Mato Grosso do Sul, 0,08-33,3\% no Nordeste (Lima et al. 2005) e 0,37\%-14,31\% no Rio Grande do Sul (Marcolongo-Pereira et al. 2011).

A maioria dos sinais clínicos relatados é condizente com o quadro clínico da raiva que se caracteriza por incoordenação dos membros pélvicos, evoluindo para paresia e paralisia, relaxamento do esfíncter anal com protrusão do ânus, ausência de reflexo anal, paralisia da cauda, tremores da cabeça, diminuição da visão, opistótono, bruxismo, salivação, fezes ressequidas e escassas, retenção e incontinência urinária e mugidos roucos (Mori \& Lemos 1998, Langohr et al. 2003).

Alguns sinais considerados pouco frequentes como cegueira e agressividade foram descritos com maior frequência que outros sinais considerados frequentes como paralisia da cauda e ausência de reflexo anal. Uma variação nos sinais clínicos também foi relatada por Lima et al. (2005). Esta variação pode ter ocorrido em virtude dos sinais relatados serem aqueles apresentados pelo animal no momento do atendimento, não incluindo sinais apresentados anterior ou posteriormente a este procedimento, outra situação é o atendimento ao surto em que os animais já se encontram mortos ou em estágio terminal. Nestas situações o exame clínico não é realizado ou é realizado de forma incompleta e muitas informações são colhidas junto ao proprietário ou responsável pelos animais favorecendo a ocorrência de interpretações imprecisas ou incorretas. Essa variação nos sinais clínicos, associado à alta prevalência da raiva no Brasil, faz com que esta seja considerada no diagnóstico diferencial das doenças do SNC (Lima et al. 2005).

Também deve ser considerada a possibilidade da não utilização de uma abordagem clínica sistematizada por parte dos médicos veterinários, assim alguns sinais importantes podem não ser descritos e outros sinais interpretados de maneira incorreta. A importância do exame clínico sistematizado e da colheita e remessa do material de forma adequada para realização dos exames necessários é ressaltada por vários autores (Riet-Correa et al. 2002 e Rissi et al. 2010).

Na maioria dos casos não foram descritos achados de necropsia significativos, porém em alguns casos (23/100) bexiga distendida e repleta foi descrita, como citado anteriormente por Lima et al. (2005). Outra alteração secundária que pode ocorrer é pneumonia aspirativa, consequência da "falsa via" durante a deglutição ou regurgitação, causada por alteração nos mecanismos fisiológicos de deglutição, devido à lesão neurológica (Barros et al. 2006), entretanto essa alteração não foi descrita nos casos observados neste estudo.

Histologicamente observou-se meningoencefalite não supurativa em todos os casos. Quando as diferentes partes anatômicas foram encaminhadas, essas lesões eram mais acentuadas na medula espinhal e tronco encefálico. Esses resultados estão de acordo com os descritos (Langohr et al. 2003, Lima et al. 2005, Silva et al. 2010). Ressalta-se que em 17 casos o cerebelo não foi encaminhado. Assim, do total de materiais no qual esta parte anatômica do SN foi encaminhada (83 casos), corpúsculos de inclusão intracitoplasmáticas nas células de Purkinje foram observados em $52 \%$. Essa frequência de observação foi menor que a relatada em outros estudos, como em 68\% (Langohr et al. 2003, Silva et al. 2010), 87\% (Lima et al. 2005), 83,3\% (Rech 2007) e maior que a encontrada por Lemos (2005) em $48 \%$. Merece destaque o fato de que os três levantamentos com menor observação de corpúsculos de inclusão foram realizados com amostras de Mato Grosso do Sul (Langohr et al. 2003, Lemos 2005 e o presente estudo). As possíveis causas desta observação são descritas detalhadamente por Langohr et al. (2003).

Houve concordância na sensibilidade diagnóstica entre as técnicas IFD, IIC e IHQ em 89 casos (93,7\%). Esses resultados corroboram com os relatos de outros autores que descrevem correlação entre a sensibilidade diagnóstica das diferentes técnicas (Pedroso et al. 2009, Achkar et al. 2010, Stein et al. 2010, Marcolongo-Pereira et al. 2011). Em outros quatro casos a IFD foi negativa e a IIC e IHQ positivas. Por outro lado, a ocorrência de resultados discrepantes entre as técnicas é descrita em bovinos (Romijn et al. 2003). Ressalta-se que no presente estudo duas amostras com quadro clínico e lesões histológicas características de raiva apresentaram resultado negativo nas provas de IFD e IIC e resultado positivo na IHQ. Esses resultados demonstram a importância da aplicação das diferentes técnicas de diagnóstico para uma mesma amostra, sendo que a IHQ pode ser utilizada em amostras negativa nas provas padrões e com lesões histológicas sugestivas de raiva mesmo que não tenham sido observados corpúsculos de Negri. No presente estudo, a IHQ foi realizada apenas em um fragmento de cada animal, dando-se preferência ao cerebelo, por ser a região na qual há maior frequência de corpúsculos de inclusão nos neurônios de Purkinje. 0 tronco encefálico foi utilizado quando não havia disponibilidade de avaliação do cerebelo. Entretanto esta metodologia não é a mais adequada, pois outros estudos demonstram que o tronco encefálico é a região de maior frequência de lesões (Langohr et al. 2003, Lima et al. 2005, Pedroso et al. 2009).

A realização da eutanásia não apresentou relação com a ocorrência de casos negativos nas provas de IFD e IIC. Dos 36 animais eutanasiados, todos foram positivos nas técnicas empregadas e apresentavam lesões histológicas compatíveis com raiva. Por outro lado, os quatro materiais negativos na IFD e positivos na IIC e IHQ e os dois negativos na IDF e IIC e positivo na IHQ tiveram morte natural. Esses resultados demonstram que a realização da eutanásia não interfere na eficiência do diagnóstico. Isto pode ser explicado pelo fato que a manifestação dos sinais clínicos neuro- 
lógicos nos casos da raiva depende da ocorrência de lesões no SN e consequentemente da presença do vírus no mesmo. Assim, se o bovino está manifestando sinais clínicos, necessariamente devem existir lesões e multiplicação do vírus no SN. Por outro lado, a distribuição do vírus da raiva no SN não é uniforme, e o vírus e as lesões distribuem-se principalmente na medula espinhal e tronco encefálico (Langohr et al. 2003, Stein et al. 2010). Alguns autores relatam que resultados falsos negativo poderiam ocorrer (Bingham \& Van der Merwe 2002).

Independente da técnica empregada, prováveis falhas no diagnóstico podem ocorrer devido ao não envio de partes anatômicas importantes para o diagnóstico como o tronco encefálico, cerebelo e medula espinhal, visto que a disposição do vírus nem sempre está presente em todo o tecido cerebral (Bingham \& Van der Merwe 2002). As lesões na medula espinhal, no cerebelo e no tronco encefálico são mais proeminentes, o que pode ser explicado pela progressão axonal centrípeta do vírus até o SNC (Swanepoel 2004). Alguns autores (Oliveira et al. 2012) mencionam que a ocorrência de resultados falso negativos poderiam ocorrer devido à realização eutanásia da eutanásia, encurtando o desenvolvimento do quadro patológico completo.

Dos 247 materiais com diagnóstico inconclusivo, em $55,06 \%$ não foram encaminhados partes anatômicas do SN pertinentes ao diagnóstico. Na grande maioria destes, os fragmentos não encaminhados correspondiam a medula e tronco encefálico. Considerando que estas são as regiões de eleição para o diagnóstico da raiva, o não encaminhando das mesmas interfere no diagnóstico laboratorial.

\section{Polioencefalomalacia (PEM)}

A PEM ocorreu em todos os meses do ano, isso já havia sido observado em outros relatos (Nakazato et al. 2000, Lemos 2005). Um único estudo realizado no MS descreve a maior ocorrência de junho a setembro (Purisco 1982). Esse autor estudou 7 casos de julho de 1979 a outubro de 1982. Riet-Correa (1984), incluindo mais 13 casos ao estudo anterior não observou a mesma sazonalidade. A ausência de sazonalidade também foi observada por outros autores (Lemos 2005, Sant'Ana et al. 2009). Em estudo mais recente, foi relatada a ocorrência de casos em todos os meses do ano (Lemos 2005), portanto sem caráter de sazonalidade.

Foram afetados bovinos com idade variando de 12 a maiores de 48 meses e a maioria dos casos ocorreu nas faixas etárias de 13 a 18 meses e 31 a 36 meses. Essas faixas etárias também foram as mais acometidas em estudos anteriores (Nakazato et al. 2000, Sant'Ana et al. 2009).

Os coeficientes de morbidade e letalidade apresentaram variação de 0,34-38,76\% e 50-100\%, respectivamente. Em outros estudos, considerando-se a população total para cálculo, os autores indicam a morbidade de 0,02-14,28\% (Nakazato et al. 2000), 0,04-6,66\% (Sant'Ana et al. 2009) e letalidade variando de 48,5\%-100\% (Nakazato et al. 2000), 43-100\% (Lemos 2005) e 50-100\% (Sant'Ana et al. 2009).

A correta avaliação epidemiológica da PEM no presente estudo encontra-se prejudicada, pois se considerou como PEM um diagnóstico morfológico para necrose com amolecimento da substância cinzenta do encéfalo (Barros et al.
2006) e não uma doença associada a um agente etiológico específico.

No presente estudo em nenhum dos casos foi identificada com precisão a etiologia das lesões do sistema nervoso, fato semelhante já foi descrito anteriormente no MS (Nakazato et al. 2000). Considerando que a PEM pode ter diferentes etiologias como deficiência de tiamina, intoxicação por enxofre, intoxicação por sal associada à privação de água e intoxicação por chumbo estas ocorrem em condições epidemiológicas distintas (Sant'Ana et al. 2009).

A PEM associada a excesso de enxofre na alimentação possui maior probabilidade de ocorrer em animais suplementados com alimentos contendo elevadas concentrações de enxofre. Já os casos de intoxicação por sódio ou privação de água tendem a ocorrer quando os animais passam por um período de privação de sal ou água e tem acesso a estes ingerindo em grande quantidade. A epidemiologia dos casos associados a deficiência de tiamina em bovinos criados extensivamente no Brasil não está bem definida, embora alguns autores associem a mudanças bruscas na alimentação (Moro et al. 1994) ou ingestão de carcaças (Purisco 1982). No presente estudo, relatou-se sucesso ao tratamento com vitamina B1 em cinco surtos. Embora esse fato possa sugerir que a maioria dos surtos esteja relacionada ao distúrbio no metabolismo da tiamina, ressalta-se que a resposta ao tratamento pode ser considerada como diagnóstico terapêutico para todas as formas de polioencefalomalacia e não apenas as causadas por deficiência de tiamina (Nakazato et al. 2000). Por outro lado, em nenhum dos casos foram descritas condições favoráveis a intoxicação por enxofre, privação de água ou intoxicação por sódio, reforçando a hipótese do envolvimento de distúrbios no metabolismo da tiamina nos surtos relatados.

A exemplo do que ocorreu com a raiva e o botulismo, a frequência dos sinais clínicos descritos apresentaram grande variação. Os sinais clínicos descritos como incoordenação, decúbito, opistótono, movimentos de pedalagem, andar em círculos, ataxia, sialorréia e nistagmo estão de acordo com relatos anteriores (Nakazato et al. 2000, Sant'Ana et al. 2009, Rissi et al. 2010), porém um sinal clínico característico da doença, que é a cegueira foi descrito em 38,64\% (17/44) dos casos. É provável que este sinal tenha ocorrido na grande maioria dos casos considerando-se que é uma das manifestações clínicas relacionada à lesão no córtex cerebral (Riet-Correa et al. 2002), e um dos principais sinais clínicos descritos em um estudo no Estado de São Paulo onde todos os bovinos afetados apresentaram esse sinal (Gonçalves et al. 2001). 0 mesmo raciocínio aplicado a raiva e o botulismo para a correta interpretação dos sinais clínicos pode ser aplicada a PEM.

Não foram mencionadas alterações macroscópicas na maioria dos casos descritos, e quando descritas, estas se restringiam ao SNC consistindo de congestão com tumefação e achatamento das circunvoluções, amolecimento e amarelamento do córtex telencefálico, focos de hemorragia no tronco encefálico e cerebelo e telencéfalo. Essas lesões estão de acordo com relatos anteriores (Nakazato et al. 2000, Sant'Ana et al. 2009). Também a ausência de lesões macroscópicas é mencionada por outros autores, a não 
observação dessas lesões provavelmente está relacionado a casos com curso clínico agudo em que as lesões não se desenvolveram a ponto de serem observadas na macroscopia ou se desenvolveram a um ponto que, embora possíveis de serem observadas, são facilmente negligenciáveis (Sant'Ana et al. 2009).

As lesões histológicas foram semelhantes a relatos anteriores da doença (Nakazato et al. 2000, Sant'Ana et al. 2009). Em nenhum caso foram observadas alterações histológicas características de intoxicação por sal.

\section{Meningoncefalite por herpesvirus bovino (BoHV)}

A Meningoncefalite por BoHV ocorreu nos meses de fevereiro a novembro, sendo o maior número de surtos nos meses de maio, setembro e outubro. Relatos anteriores também não mencionam a ocorrência de sazonalidade (Salvador et al. 1998, Colodel et al. 2002, Elias et al. 2004).

Foram acometidos predominantemente bovinos com idade entre 13 a 24 meses. Um caso em bezerro com idade inferior a 6 meses e dois casos em animais maiores de 48 meses também foram diagnosticados. A predominância em bovinos de 13 a 24 meses, e a ocorrência eventual em animais abaixo de 1 ano e acima de 48 meses também é descrita (Salvador et al. 1998, Colodel et al. 2002, Rissi et al. 2008).

Os coeficientes de morbidade na população sob risco foram de 0,79-5,0\%. Outros estudos revelam grande variação na morbidade da doença, a qual geralmente é baixa quando considerada a população total, como 0,05 a 6,5\% (Salvador et al. 1998) e 0,76 a $6,65 \%$, chegando a $25 \%$ em um surto (Eliasmet al. 2004). Em um estudo realizado no Mato Grosso, o coeficiente de morbidade foi elevado quando considerados apenas os bovinos do lote em que estão ocorrendo os casos (população sob risco), atingindo até 22\% (Colodel et al. 2002). A letalidade variou de 37,5 a $100 \%$, sendo a letalidade média 91,9\%. Esses valores indicam que os coeficientes de letalidade na maioria dos surtos se aproximam de 100\%, como o relatado por Colodel et al. (2002). É possível que os dados de morbidade e letalidade não sejam exatos, uma vez que as informações coletadas eram referentes apenas ao momento da remessa do material ao laboratório, sem posterior acompanhamento.

Em apenas dois surtos foram descritos a introdução de animais de diferentes origens em uma mesma propriedade, que é considerado um fator predisponente para a ocorrência da doença (Colodel et al. 2002). Este padrão epidemiológico pode ser explicado pela patogenia dos herpesvírus, que possui característica de latência, o que permite ao agente se manter por tempo indeterminado nos indivíduos infectados sem desenvolvimento de manifestações clínicas, esta capacidade foi demonstrada em condições experimentais por Perez et al. (2002) e Vogel et al. (2003). A reativação do vírus pode ocorrer naturalmente ou em situações de estresse, gerando condições para o transporte e disseminação do agente a outros indivíduos suscetíveis (Caron et al. 2002, Rissi et al. 2007). Casos de encefalite por herpesvírus bovino são comumente relatados em bovinos submetidos a fatores de estresse, como desmame (Elias et al. 2004, Rissi et al. 2006), vacinação, troca de alimentação, castração, troca de piquetes (Elias et al. 2004), transporte, aglomeração e introdução de animais de outro rebanho (Rissi et al. 2008). Lemos (2005) relata a ocorrência de dois surtos no MS após a introdução de animais na propriedade, sugerindo que esses bovinos possam ter introduzido o vírus. Por outro lado, nos demais surtos não foram relatados fatores predisponentes para a ocorrência dos mesmos.

Os sinais clínicos descritos referem-se principalmente a distúrbios corticais e em sua maioria estão de acordo com a literatura consultada. Alguns sinais clínicos fortemente sugestivos da doença, como depressão e cegueira foram descritos respectivamente em $45,5 \%$ e $54,6 \%$ dos casos. Considerando que as formas encefálicas do herpesvirus bovino caracterizam-se por necrose do córtex cerebral, a exemplo do que foi descrito na PEM, é provável que estes animais tenham manifestado estes sinais e não tenham sido descritos pelos mesmos motivos citados na PEM.

Uma característica clínica observada nos casos acompanhados pela equipe do LAP foi que bovinos com quadro de herpesvírus manifestavam depressão desde os estágios iniciais da doença. Esta observação pode ser útil no diagnóstico diferencial para polioencefalomalacia originada por outras causas, como a deficiência de tiamina ou intoxicação por sal e enxofre (Sant'Ana et al. 2009). Nessas condições a depressão pode ocorrer em estágios avançados, mas geralmente é precedida por agressividade.

Os principais achados de necropsia descritos se restringiam ao sistema nervoso central e consistiam de áreas de malacia caracterizadas por áreas deprimidas, de coloração amarelada ou avermelhada no córtex cerebral. Histologicamente havia meningoencefalite não supurativa associada à necrose do córtex cerebral. Em todos os casos, tanto macroscopicamente como microscopicamente as lesões eram bilaterais embora nem sempre simétricas. Corpúsculos de inclusão intranucleares em neurônios e astrócitos foram observados em 7 casos (21,2\%). Corpúsculos de inclusão são frequentemente relatados em casos espontâneos da enfermidade (Riet-Correa et al. 1989, Salvador et al. 1998, Sanches et a. 2000, Colodel et al. 2002, Elias et al. 2004, Riet-Correa et al. 2006), entretanto no presente estudo a observação de corpúsculo foi baixa em relação a algum destes, como 85,7\% (Salvador et al. 1998) e 100\% (Colodel et al. 2002, Elias et al. 2004).

Em 30 casos foi realizada a imuno-histoquímica com anticorpo monoclonal para herpesvirus bovino tipo 5, sendo observada marcação positiva em 14 casos. Salienta-se que em dois surtos nos quais foram encaminhadas mais de uma amostra para o exame houve discrepância nos resultados. No primeiro surto, de quatro amostras, três apresentaram marcação positiva e no outro surto, de seis amostras encaminhadas, apenas uma apresentou marcação positiva. Considerando que as lesões histológicas características eram semelhantes em todos os casos, estes resultados sugerem que a técnica pode apresentar baixa sensibilidade, ou o tempo de fixação possivelmente possa ter interferido no processo de imuno-marcação. Apesar das diferenças, esses resultados também demonstram que a técnica de imuno-histoquímica pode ser utilizada como método adequado para identificação do agente em amostras fixadas em for- 
mol, como o relatado por Hübner et al. (2005) e De Paula et al. (2005).

É possível que casos de meningoencefalite não supurativa sejam causados por herpesvirus bovino tipo 1 (Rissi et al. 2008) os quais poderiam não ser detectados com a utilização de anticorpo monoclonal para herpesvirus bovino tipo 5. No entanto, estudos anteriores demonstram que o BoHV tipo 5 foi o agente identificado em Mato Grosso (Arruda et al. 2010).

\section{Outras doenças}

Dentre as outras doenças diagnosticadas no período estudado, os casos de meningoencefalite não supurativa sem causa específica foram os diagnósticos de maior prevalência $(2,62 \%)$. Esta alteração histológica é compatível com infecção viral, e em levantamento anterior realizado no MS o percentual deste diagnóstico foi de $20 \%$ entre o total de doenças do sistema nervoso diagnosticadas. Naquele estudo a maioria dos casos apresentava epidemiologia, quadro clínico e distribuição e característica histológicas de lesões sugestivas de raiva. No presente levantamento, 13 casos foram testados para raiva pela IHQ, e todos apresentando resultado negativo. Estes dados indicam que outras infecções virais, como o BoHV podem ser responsáveis por quadro de meningoencefalite não supurativa no estado e que não estão sendo diagnosticadas com as técnicas empregadas na rotina. Ressalta-se que destes surtos, sete não enviaram todas as partes anatômicas do SN pertinentes ao diagnóstico, dificultando a avaliação histológica.

Os casos de meningoencefalite supurativa e também abscessos do SN ou de estruturas adjacentes que comprimem o sistema nervoso em conjunto totalizaram 2,81\% dos diagnósticos realizados. Embora não tenha sido realizado o isolamento bacteriano, a maioria destes casos são infecções neonatais, que possuem como fator predisponente a cura de umbigo e a ingestão de colostro inadequada pelos bezerros. Os agentes envolvidos são as bactérias piogênicas responsáveis por diversas manifestações clínicas. Entre os agentes, em bovinos estão Streptococcus spp., Enterococus spp., Fusobacterium nucleatum, Pseudomonas aeruginosa, Klebsiella spp., Arcanobacterium (Actinomyces) pyogenes, Pasteurella spp. Sorovares de Salmonella, Haemophilus somnus, Listeria monocytogenes e Escherichia coli (Radostits et al. 2007).

Merece destaque um caso de compressão medular por abscesso de vértebra que ocorreu em uma vaca pardo suíço. Não foi identificado o fator predisponente para ocorrência desta em animais adultos, entretanto o rebanho apresentava alta infestação de carrapatos originando miíases e dermatite em vários animais, sugerindo a pele como porta de entrada da infecção. A ocorrência de compressão medular por abscessos foi relatada em reações vacinais após a aplicação de vacina contra aftosa (Ubiali et al. 2011, Marques et al. 2012). Embora seja cogitada como possível causa, a aplicação de medicamentos com equipamentos contaminados, não havia histórico desse bovino receber aplicação de medicamentos na região lombar, nem evidência de reações inflamatórias na região do abscesso.

Outro aspecto a ser ressaltado é que a maioria dos diagnósticos de compressão medular por abscesso (5/7) ocorreu em bovinos necropsiados pela equipe do LAP. É provável que isto se deva ao acompanhamento clínico e a realização de necropsia com exame detalhado da coluna vertebral e da medula realizada nestes casos em função da suspeita clínica. Nos materiais remetidos, com quadro de distúrbios nervosos, apenas o encéfalo foi encaminhado, não permitindo um diagnóstico conclusivo.

Dos 6 surtos de tétano quatro foram diagnosticados por médicos veterinários do LAP. Entre os surtos havia histórico de cirurgia de colocação de cânula, orquiectomia e cura inadequada de umbigo, que são considerados como fatores predisponentes para a infecção (Radostits et al. 2007).

Os surtos de hipotermia aqui citados foram descritos detalhadamente em conjunto com a ocorrência da doença no estado em anos anteriores por Santos et al. (2012). Salienta-se que no presente estudo os surtos ocorreram em apenas dois anos, e no mesmo mês, o que se deve ao fato desta doença no MS ser provocada principalmente por mudanças climáticas bruscas, com declínio acentuado de temperatura ambiente acompanhada por chuvas e ventos.

No presente estudo foram diagnosticados quatro surtos de babesiose cerebral. Essa doença não havia sido diagnosticada em levantamento realizado anteriormente (Lemos 2005). 0 aparecimento da doença possivelmente está relacionado ao aumento da população de bovinos de raças europeias ou cruza de nelore com estas raças no MS. Ressalta-se que nos casos diagnosticados dois foram em animais de raças europeias (pardo suíço) e dois em bovinos nelore, os quais estavam infestados por carrapatos e eram criados em áreas nas quais foram anteriormente ocupadas por animais cruzados. Os sinais clínicos e os achados macroscópicos e histológicos foram semelhantes aos relatados por Rodrigues et al. (2005) e Antoniassi et al. (2009).

Dois surtos de febre catarral maligna e um com lesões de intoxicação por oxalato foram diagnosticados com base nas lesões histológicas. Surtos de febre catarral maligna foram descritos anteriormente no estado (Lemos et al. 2005). 0 surto sugestivo de intoxicação por oxalato ocorreu em pastagem de Brachiaria humidicola na região do pantanal, e os bovinos apresentaram sinais compatíveis com distúrbios nervosos e neuromusculares. Embora essa intoxicação se caracterize por lesões renais (nefrose por oxalatos), sinais clínicos compatíveis com distúrbios neurológicos são provocados pela hipocalcemia (Tokarnia et al. 2012). Esta observação é importante, pois em muitos casos com sinais clínicos sugestivos de quadros nervosos apenas o SN é encaminhado para o exame histológico, e nestes casos o envio do rim é fundamental para o diagnóstico (Rech et al. 2005, Lemos et al. 2005).

Os resultados obtidos demonstram que as doenças do sistema nervoso apresentam sinais clínicos comuns entre si de maneira que o diagnóstico definitivo exige a realização de exames laboratoriais. 0 diagnóstico conclusivo pode ser realizado com sucesso na maioria das doenças quando são colhidos dados epidemiológicos, sinais clínicos e amostras para exame complementar de forma sistematizada.

Nas doenças que causam lesões histológicas características como a PEM, a raiva, a encefalite por herpesvirus e 
a febre catarral maligna, o não envio do histórico correto, embora importante, não impossibilita o diagnóstico desde que sejam encaminhadas as partes anatômicas pertinentes ao diagnóstico. No caso de doenças que não provocam lesões macroscópicas ou histológicas como o tétano e o botulismo, o não envio do histórico epidemiológico e clínico impossibilita o diagnóstico. Nestes casos ressalta-se que o não encaminhamento de fragmentos de musculatura esquelética ou da medula espinhal e do tronco encefálico também impossibilita o diagnóstico, pois isto não permite a eliminação de outras possíveis causas dos sinais nervosos ou confundíveis com estes como a raiva ou as miopatias tóxicas e nutricionais. Por outro lado, sinais clínicos característicos de algumas doenças, como a cegueira na PEM e na encefalite por herpesvirus, a paralisia de cauda na raiva e no botulismo e a ausência e reflexo anal na raiva são pouco descritos nos laudos. Considerando a patogenia destas doenças e também os resultados dos exames histológicos do presente estudo, estes sinais ocorrem em maior frequência do que são descritos e poderia ser utilizado como critério para o estabelecimento do diagnóstico clínico.

0 mesmo raciocínio pode ser aplicado aos dados epidemiológicos. Algumas condições que são características de determinadas doenças como a ocorrência de casos em diferentes espécies animais, diferentes faixas etárias e diferentes pastos da propriedade em surtos de raiva, ou a ocorrência de casos em um mesmo lote de animais de uma única espécie nos surtos de botulismo, não são enfatizadas na maioria dos históricos. Considerando-se a epidemiologia destas doenças, estas características poderiam ser utilizadas para formular ou eliminar uma suspeita clínica.

\section{CONCLUSÕES}

As doenças do sistema nervoso são responsáveis por importantes prejuízos econômicos no Mato Grosso do Sul.

O botulismo, a raiva, a PEM e a encefalite por herpesvirus são as principais causas de mortalidade associadas a distúrbios nervosos no estado.

A metodologia empregada permite realizar o diagnóstico conclusivo na maioria dos casos, entretanto, o não encaminhamento de dados epidemiológicos, sinais clínicos e a remessa inadequada de amostras para exame laboratorial são responsáveis pelo elevado número de diagnósticos inconclusivos.

\section{REFERÊNCIAS}

Achkar S.M., Fernandes E.R., Carrieri M.L., Castro A.B.M., Batista A.M., Duarte M.I.S. \& Kotait I. 2010. Sensibilidade da técnica de imuno-histoquímica em fragmentos de sistema nervoso central de bovinos e equinos naturalmente infectados pelo vírus da raiva. Pesq. Vet. Bras. 30(3):211218.

Antoniassi N.A.B., Corrêa A.M.R., Santos A.S., Pavarini S.P., Sonne L., Bandarra P.M. \& Driemeier D. 2009. Surto de babesiose cerebral em bovinos no Estado do Rio Grande do Sul. Ciência Rural 39(3):933-936.

Arruda L.P., Nakazato L., Dutra V., Lemos R.A.A., Nogueira A.P.A., Cruz R.A.S., Pescador C.A. \& Colodel E.M. 2010. Detecção molecular de herpesvírus bovino 1 e 5 em amostras de encéfalo conservadas em formol e emblocadas em parafina provenientes de bovinos com doença neurológica. Pesq. Vet. Bras. 30(8):646-650.

Barros C.S.L., Driemeier D., Dutra I.S. \& Lemos R.A.A. 2006. Doenças do sistema nervoso de bovinos no Brasil. Agnes, Montes Claros. 207p.
Bingham J. \& Van Der Merwe M. 2002. Distribution of rabies antigen in infected brain material: determining the reliability of different regions of the brain for the rabies fluorescent antibody test. J. Virol. Methods. 101: 85-94.

Brambell J.W.R. 1958. The passive immunity of young mammal. Biol. Rev. 33:488-531.

Brasil 2002. Instrução Normativa ํㅜ 5, de 1 de março de 2002, aprova as Normas Técnicas para o controle da raiva dos herbívoros domésticos. Diário Oficial da União de 4 de março de 2002, Seção 1, p.3.

Carmo P.M.S., Irigoyen L.F., Lucena R.B., Fighera R.A., Kommers G.D. \& Barros C.S.L. 2011. Spontaneous coffee senna poisoning in cattle: Report on 16 outbreaks. Pesq. Vet. Bras. 31(2):139-146.

Caron L., Flores E.F., Weiblen R., Scherer C.F., Irigoyen L.F., Roehe P.M., Odeon A. \& Sur J.H. 2002. Latent infection by bovine herpesvirus type-5 in experimentally infected rabbits: virus reactivation, shedding and recrudescence of neurological disease. Vet. Microbiol. 84:285-295.

Carvalho N.M., Alonso L.A., Cunha T.G., Ravedutti J., Barros C.S.L. \& Lemos R.A.A. 2006. Intoxicação de bovinos por Tetrapterys multiglandulosa (Malpighiaceae) em Mato Grosso do Sul. Pesq. Vet. Bras. 26(3):139-146.

Carvalho N.M., Bacha F.B., Santos A.C., Carvalho A.Q., Faccin T.C., Pott A. \& Lemos R.A.A. 2013. Spontaneous and experimental intoxication of cattle by Simarouba versicolor A. St. Hil. (Simaroubaceae). Toxicon 64:55-59.

Colodel E.M., Nakazato L., Weiblen R., Mello R.M., Silva R.R.P., Souza M.A., Filho J.A.O. \& Caron L. 2002. Meningoencefalite necrosante em bovinos causada por herpesvírus bovino no estado de Mato Groso, Brasil. Ciência Rural 32:293-298.

De Paula R.R., Souza M.A., Colodel E.M., Hübner S.O., Brum K.B., Jorge K.B.C. \& Damasceno A.D. 2005. Meningoencefalite causada pelo BHV-5 em um bovino no Estado de Goiás. Arq. Bras. Med. Vet. Zootec. 57(Supl.1):2.

Dutra I.S. 2001. Epidemiologia, quadro clínico e diagnóstico pelo soro neutralização em camundongos do botulismo em bovinos no Brasil, 19892000. Tese de Livre-Docência, Curso de Medicina Veterinária, Universidade Estadual Paulista, Campus de Araçatuba. 133p.

Dutra I.S., Döbereiner J. \& Souza A.M. 2005. Botulismo em bovinos de corte e leite alimentados com cama de frango. Pesq. Vet. Bras. 25(2):115-119.

Elias F., Schild A.L. \& Riet-Correa F. 2004. Meningoencefalite e encefalomalacia por herpesvírus bovino-5: distribuição das lesões no sistema nervoso central de bovinos naturalmente infectados. Pesq. Vet. Bras. $24: 123-131$.

Fernandes C.G. \& Riet-Correa F. 2007. Doenças víricas, p.184-198. In: Riet-Correa F., Schild A.L., Lemos R.A.A. \& Borges J.R. (Eds), Doenças de Ruminantes e Eqüídeos. Vol.1. 3 a ed. Pallotti, Santa Maria, RS.

Galiza G.J.N., Silva M.L.C.R., Dantas A.F.M., Simões S.V.D. \& Riet-Correa F. 2010. Doenças do sistema nervoso de bovinos no semiárido nordestino. Pesq. Vet. Bras. 30(3):267-276.

Gonçalves R.C., Viana L., Sequeira J.L., Bandarra E.P., Chiacchio S.B. \& Kuchembuck M.R.G. 2001. Aspectos clínicos, anatomopatológicos e epidemiológicos da polioencefalomalacia em bovinos, na região de Botucatu, SP. Vet. Notícias 7:53-57.

Hübner S.O., Pescador C., Corbellini L.G., Driemeier D., Spilki F.R. \& Roehe P.M. 2005. Otimização da imunoistoquímica para detecção de herpesvírus bovino tipo 5 (BHV-5) em tecidos do sistema nervoso central fixados com formaldeído. Arq. Bras. Med. Vet. Zootec. 57:1-6.

Kotait I., Gonçalves C.A., Peres N.F., Souza M.C.A.M. \& Targueta M.C. 1998. Controle da raiva dos herbívoros. Manual Técnico do Instituto Pasteur, São Paulo, 1:15

Langohr I.M., Irigoyen L.F., Lemos R.A.A. \& Barros C.S.L. 2003. Aspectos epidemiológicos, clínicos e distribuição das lesões histológicas no encéfalo de bovinos com raiva. Ciência Rural 33:125-131.

Lemos R.A.A. 2005. Enfermidades do sistema nervoso de bovinos de corte das regiões Centro-oeste e Sudeste do Brasil. Tese de Doutorado, Universidade Estadual Paulista "Julio de Mesquita Filho", Jaboticabal. 149p.

Lemos R.A.A., Rech R.R., Guimarães E.B., Kadri A. \& Dutra I.S. 2005. Febre catarral maligna em bovinos do Mato Grosso do Sul e de São Paulo. Ciência Rural 35(4):932-934.

Lima E.F., Riet-Correa F., Castro R.S., Gomes A.A.B. \& Lima F.S. 2005. Sinais clínicos, distribuição das lesões no sistema nervoso e epidemiologia da raiva em herbívoros na região Nordeste do Brasil. Pesq. Vet. Bras. 25(4):250-264. 
Marcolongo-Pereira C., Sallis E.S.V., Grecco F.B., Raffi M.B., Soares M.P. \& Schild A.L. 2011. Raiva em bovinos na Região Sul do Rio Grande do Sul: epidemiologia e diagnóstico imuno-histoquímico. Pesq. Vet. Bras. 31(4):331-335.

Marques A.L.A., Simões S.V.D., Maia L.A., Silva T.R., Neto E.G.M., Pimentel L.A., Afonso J.A.B. \& Dantas A.C. 2012. Compressão medular em bovinos associada à vacinação contra febre aftosa. Ciência Rural 42(10):18511854.

Maxie M.G. 2007. Jubb, Kennedy and Palmer's Pathology of Domestic Animals. Vol.1. $5^{\text {th }}$ ed. Saunders Elsevier, Toronto, p.413-416.

Meyer G., Lemaire M., Ros C., Belak K., Gabriel A.. Cassart D., Coignoul F., Belak S. \& Thiry E. 2001. Comparative pathogenesis of acute and latent infections of calves with bovine herpesvirus types 1 and 5. Arch. Virol. 146:633-652.

Mori A.E. \& Lemos R.A.A. 1998. Raiva, p.47-58. In: Lemos R.A.A. (Ed.), Principais Enfermidades de Bovinos de Corte do Mato Grosso do Sul: reconhecimento e diagnóstico. UFMS, Campo Grande, MS.

Mori A.E., Lemos R.A.A. \& Kadri A. 2004. Raiva, p.63-86. In: Lemos R.A.A. (Ed.), Série Qualificação Rural 2:63-86.

Moro L., Nogueira R.H.G., Carvalho A.U. \& Marques D.C. 1994. Relato de três casos de polioencefalomalacia em bovinos. Arq. Bras. Vet. Zootec. 46:409-416.

Nakazato L., Lemos R.A.A. \& Riet-Correa F. 2000. Polioencefalomalacia em bovinos nos estados de Mato Grosso do Sul e São Paulo. Pesq. Vet. Bras. 20(3):119-125.

Njaa B.L., Panciera R.J., Clark E.G. \& Lamm C.G. 2012. Gross Lesions of Alimentary Disease in Adult Cattle. Vet. Clin. Food Anim. 28:483-513.

Oliveira T.S., Bull V., Rezende C.A., Furtini R., Costa E.A., Paixão T.A. \& Santos R.L. 2012. Perfil das amostras do sistema nervoso central de bovinos com síndrome neurológica e diagnóstico da raiva bovina no serviço de defesa sanitária de Minas Gerais, 2003-2010. Pesq. Vet. Bras. 32(4):333339.

Pedroso P.M.O., Pescador C.A., Bandarra P.M., Raymundo D.L., Borba M.R., Wouters F., Bezerra Jr P.S. \& Driemeier D. 2008. Padronização da técnica de imuno-histoquímica para raiva em amostras de tecido do sistema nervoso central de bovinos fixadas em formol e emblocadas em parafina. Pesq. Vet. Bras. 28(12):627-632.

Pedroso P.M.O., Colodel E.M., Pescador C.A., Arruda L.P. \& Driemeier D. 2009. Aspectos clínicos e patológicos em bovinos afetados por raiva com especial referência ao mapeamento do antígeno rábico por imuno-histoquímica. Pesq. Vet. Bras. 29(11):899-904.

Perez S.E., Bretschneider G., Leunda M.R., Osório F.A., Flores E.F. \& Odeón A.C. 2002. Primary infection, latency, and reactivation of Bovine Herpesvirus type 5 in the bovine nervous system. Vet. Pathol. 39:437-444.

Purisco E. 1982. Ocorrência de Polioencefalomalacia em Bovinos no Estado de Mato Grosso do Sul. Monografia de Especialização, Universidade Federal de Mato Grosso do Sul, Campo Grande, MS. 25p.

Radostits O.M., Gay C.C., Hinchcliff K.W. \& Constable P.D. 2007. (Eds), Veterinary Medicine: a textbook of the diseases of cattle, horses, sheep, pigs, and goats. $10^{\text {th }}$ ed. Saunders Elsevier, Philadelphia.

Rech R.R. 2007. Alterações no encéfalo de bovinos submetidos à vigilância das encefalopatias espongiformes transmissíveis. Tese de Doutorado, Universidade Federal de Santa Maria, Santa Maria, RS. 228p.

Rech R.R., Schild A.L., Driemeier D., Garmatz S.L., Oliveira F.N., Riet-Correa F. \& Barros C.S.L. 2005. Febre catarral maligna em bovinos no Rio Grande do Sul: epidemiologia, sinais clínicos e patologia. Pesq. Vet. Bras. 25(2):97-105.

Riet-Correa F. 1984. Avaliação econômica e epidemiológica dos problemas sanitários do rebanho de Mato Grosso do Sul. Relatório. 40p.

Riet-Correa F., Vidor T., Schild A.L. \& Méndez M.C. 1989. Meningoencefalite e necrose do córtex cerebral em bovinos por herpesvírus bovino-1. Pesq. Vet. Bras. 9:13-16.

Riet-Correa F., Schild A.L. \& Fernandes C.G. 1998. Enfermidades do sistema nervoso dos ruminantes no sul do Rio Grande do Sul. Ciência Rural 28(2):341-348.

Riet-Correa F., Riet-Correa G. \& Schild A.L. 2002. Importância do exame clínico para o diagnóstico das enfermidades do sistema nervoso em ruminantes e equídeos. Pesq. Vet. Bras. 22(4):161-168.
Riet-Correa G., Duarte M.D., Barbosa J.D., Oliveira C.M.C., Cerqueira V.D., Brito M.F. \& Riet-Correa F. 2006. Meningoencefalite e polioencefalomalacia causadas por Herpesvírus bovino-5 no estado do Pará. Pesq. Vet. Bras. 26(1):44-46.

Rissi D.R., Oliveira F.N., Rech R.R., Pierezan F., Lemos R.A.A. \& Barros C.S.L. 2006. Epidemiologia, sinais clínicos e distribuição das lesões encefálicas em bovinos afetados por meningoencefalite por herpesvírus bovino- 5 . Pesq. Vet. Bras. 26(2):123-132.

Rissi D.R., Rech R.R., Flores E.F., Kommers G.D. \& Barros C.S.L. 2007. Meningoencefalite por herpesvírus bovino-5. Pesq.Vet. Bras. 27(7):251-260.

Rissi D.R., Pierezan F., Silva M.S., Flores E.F. \& Barros C.S.L. 2008. Neurological disease in cattle in southern Brazil associated with Bovine herpesvirus infection. J. Vet. Diagn. Invest. 20:346-349.

Rissi D.R., Pierezan F., Oliveira-Filho J.C., Lucena R.B., Carmo P.M.S. \& Barros C.S.L. 2010. Abordagem diagnóstica das principais doenças do sistema nervoso de ruminantes e equinos no Brasil. Pesq. Vet. Bras. 30(11):958-967.

Rodrigues A., Rech R.R., Barros R.R., Fighera R.A. \& Barros C.S.L. 2005. Babesiose cerebral em bovinos: 20 casos. Ciência Rural 35(1):121-125.

Romijn P.C., Van der Heide R., Cattaneo C.A., Silva R.C.F. \& Van Der Porl W.H.M. 2003. Study of Lyssaviruses of bat origin as a source of rabies for other animal species in the State of Rio de Janeiro, Brazil. Am. J. Trop. Med. Hyg. 69:81-86.

Salvador S.C., Lemos R.A.A., Riet-Correa F., Roehe P.M. \& Osório A.L.A.R. 1998. Meningoencefalite em bovinos causada por herpesvírus bovino-5 no Mato Grosso do Sul e São Paulo. Pesq. Vet. Bras. 18(2):76-83.

Sanches A.W.D., Langohr I.M., Stigger A.L. \& Barros C.S.L. 2000. Doenças do sistema nervoso central em bovinos no Sul do Brasil. Pesq. Vet. Bras. 20(3):113-118.

Sant'Ana F.J.F., Rissi D.R., Lucena R.B., Lemos R.A.A., Nogueira A.P.A. \& Barros C.S.L. 2009. Polioencefalomalacia em bovinos: epidemiologia, sinais clínicos e distribuição das lesões no encéfalo. Pesq. Vet. Bras. 29(7):487497.

Santos A.C., Carvalho N.M., Sá Ribas N.L.K., Travassos A.G.S., Leal P.V. \& Lemos R.A.A. 2011. Surtos de intoxicação por Senna occidentalis e Senna obtusifolia em bovinos a pastoreio. IX Congresso Brasileiro de Buiatria, Goiânia/GO. FMVZ, Botucatu, Vol.1, p.523-526.

Santos B.S., Pinto A.P., Aniz A.C.M., Almeida A.P.M.G., Franco G.L., Guimarães E.B. \& Lemos R.A.A. 2012. Mortalidade de bovinos zebuínos por hipotermia em Mato Grosso do Sul. Pesq. Vet. Bras. 32(3):204-210.

Silva J.A., Moreira E.C., Haddad J.P.A., Modena C.M. \& Tubaldini M.A.S. 2001. Distribuição temporal e espacial da raiva bovina em Minas Gerais, 19761977. Arq. Bras. Med. Vet. Zootec. 53(3):263-272.

Silva M.L.C.R., Riet-Correa F., Galiza G.J.N., Azevedo S.S., Afonso J.A.B. \& Gomes A.A.B. 2010. Distribuição do vírus rábico no sistema nervoso central em ruminantes naturalmente infectados. Pesq. Vet. Bras. 30(11):940-944.

Stein L.T., Rech R.R., Harrison L. \& Brown C.C. 2010. Immunohistochemical study of rabies virus within the central nervous system of domestic and wildlife species. Vet. Pathol. 47:630-633.

Swanepoel R. 2004. Rabies, p.1123-1182. In: Coetzer J.A.W. \& Tustin R.C. (Eds), Infectious Diseases of Livestock. Vol.2. Oxford University Press, Cape Town.

Teixeira T.F., Holz C.L., Caixeta S.P.M.B., Dezen D., Cibulski S.P., Silva J.R., Rosa J.C.A., Schmidt E., Ferreira J.C., Batista H.B.C.R., Caldas E., Franco A.C. \& Roehe P.M. 2008. Diagnóstico de raiva no Rio Grande do Sul, Brasil, de 1985 a 2007. Pesq. Vet. Bras. 28(10):515-520.

Tokarnia C.H., Brito M.F., Barbosa J.D., Peixoto P.V. \& Döbereiner J. 2012. Plantas Tóxicas do Brasil. 2ª ed. Editora Helianthus, Rio de Janeiro. 586p.

Turner D. 1975. The Vampire Bat. Johns Hopkins University Press, London. $145 \mathrm{p}$

Ubiali D.G., Cruz R.A.S., Lana M.V.C., Meireles Y.S., Néspoli P.B., Souza M.A., Colodel E.M. \& Pescador C.A. 2011. Spinal cord compression in cattle after the use an oily vaccine. Pesq. Vet. Bras. 31(11):997-999.

Vogel F.S., Caron L., Flores E.F., Weiblen R., Winkelmann E.R., Mayer S.V. \& Bastos R.G. 2003. Distribuiton of bovine herpesvirus type 5 DNA in the central nervous system of latently, experimentally infected calves. J. Clin. Microbiol. 41(10):4512-4520. 